\title{
Cerebrovascular complications during pregnancy and postpartum
}

Jeong-Ho Hong, MD, PhD

Department of Neurology, Brain Research Institue, Keimyung University Dongsan Hospital, Keimyung University School of Medicine, Daegu, Republic of Korea
Journal of

Neurocritical

\section{Care}

\section{REVIEW ARTICLE}

Received: June 9, 2019

Revised: June 20, 2019

Accepted: June 20, 2019

Corresponding Author:

Jeong-Ho Hong, MD, PhD

Department of Neurology, Brain Research Institue, Keimyung University Dongsan Hospital, Keimyung University School of Medicine, 1095 Dalgubeol-daero, Dalseogu, Daegu 42601, Republic of Korea

Tel: +82-53-258-7839

Fax: +82-53-258-4380

E-mail: neurohong79@gmail.com

Cerebrovascular complications that more likely to occur during pregnancy or postpartum include cerebral venous thrombosis, ischemic and hemorrhagic stroke, posterior reversible encephalopathy syndrome, and postpartum angiopathy, which although rare, can lead to serious outcomes for both mother and fetus. Pregnancy is a very unique condition, especially, in terms of treatment and, as such, neurointensivists must always consider its potential effects on the fetus. The purpose of this review is to help understand the physiological changes during pregnancy and postpartum, and to inform treatment decisions regarding pregnancy-related cerebrovascular complications.

Keywords: Critical care; Pregnancy complications; Venous thromboembolism; Hypertension, pregnancy-induced; Stroke

\section{INTRODUCTION}

Pregnancy-associated neurocritical complications involve various diseases. Myasthenia gravis can be worsened in approximately $30 \%$ to $40 \%$ of women during pregnancy or during the postpartum period [1]. The relapse rate of multiple sclerosis increases in the 3 months postpartum [2]. Approximately one-third of pregnant women with epilepsy can experience worsening of seizure control due to various factors such as psychological stress, sleep deprivation, altered drug disposition, poor drug compliance due to fear of teratogenicity, increased estrogen levels leading to decline in seizure threshold, and decreased serum levels of antiepileptic drugs
[3-5]. Pregnancy-related cerebrovascular disorder is one of the major causes of maternal mortality. In the present review, we focus especially on cerebrovascular complications during pregnancy and postpartum. These complications are closely related to physiological changes during pregnancy. Thus, it is important to understand the changes in the hemodynamic, vascular structural, and coagulation systems that can occur during pregnancy.

\section{WHAT HAPPENS DURING PREGNANCY?}

Cardiac output and blood volume increase $30 \%$ to $50 \%$ until late in the second trimester due to maternal hypervolemia and the de- 
veloping fetus [6-8]. However, increased nitric oxide and prostacyclin levels cause systemic vascular resistance to begin to lower blood pressure [9]. In addition, increased venous capacitance compromises venous stasis, which leads to orthostatic intolerance $[10,11]$. Concurrently, the collagen and elastin content of systemic arteries decrease $[10,12]$. More vulnerable vessel walls encounter greater hemodynamic stress. Both hemodynamic and structural changes in vessel walls during pregnancy can contribute to the increased risk for various hemorrhagic conditions in the brain.

In the third trimester of pregnancy and the early puerperium period, venous congestion, aortocaval compression by gravid uterus, and vascular damage related to vaginal or cesarean section delivery can induce hypercoagulability [13-15]. Biochemical changes, such as increased procoagulants (Factors VII, VIII, and X) and decreased coagulation inhibitors (antithrombin III and protein S) in late pregnancy, also result in a hypercoagulable state (Fig. 1) [15-17].

\section{RISK FACTORS FOR THROMBOEMBOLISM DURING PREGNANCY AND POSTPARTUM}

The strongest risk factors for venous thromboembolism (VTE) is a history of thrombosis, and pregnancy-related hypertension for both ischemic and hemorrhagic stroke during pregnancy and puerperium $[16,17]$. According to population-based studies, advanced maternal age ( $>35$ years), obesity (body mass index $>30$ $\left.\mathrm{kg} / \mathrm{m}^{2}\right)$, multiple births, and multiple gestation are characteristics that can increase the risk for thromboembolism $[16,18]$. In terms of medical conditions and pregnancy complications, heart disease, systemic lupus erythematosus, immobilization, smoking, inflammatory bowel disease, cesarean delivery, preterm delivery ( $<36$ weeks), transfusion, preeclampsia and eclampsia can amplify the maternal thromboembolic risk $[16,19,20]$. The inherited thrombophilias associated with thromboembolism in pregnancy is a genetic tendency of VTE in particular. Factor V Leiden mutation and prothrombin 20210A mutation are more common inherited thrombophilias in Caucasian populations [21]. However, Kim et al. [22] reported that a Factor V Leiden mutation and a prothrombin 20210A mutation was not found in 228 Korean patients with VTE. Another study also reported no Factor V Leiden mutation in Korean patients with deep vein thrombosis (DVT). As such, these inherited thrombophilias appear to be extremely rare in Asian populations, including Koreans with DVT [23]. On the other hand, deficiencies in antithrombin, protein $\mathrm{S}$ and protein $\mathrm{C}$, and antiphospholipid syndrome, are relatively common in Korean populations, and are stronger risk factors [22,24-27].

Pregnancy-related hypertensive disorder is one of the leading causes of neurocritical illness in the perinatal or postnatal periods $[28,29]$. In particular, preeclampsia, eclampsia and HELLP syndrome (hemolysis with a microangiopathic blood smear, elevated liver enzymes and low platelets) represent the most important spectrum of pregnancy-related hypertensive disorders in the latter half of pregnancy or postpartum, which lead to increased risk for thromboembolic and hemorrhagic complications [28]. In 2019, the American College of Obstetricians and Gynecologists listed diagnostic criteria for preeclampsia (Table 1) [30]. Eclampsia (convulsive manifestation of preeclampsia) and HELLP syndrome are more severe forms of preeclampsia [30].

\section{VENOUS THROMBOEMBOLIC COMPLICATIONS DURING PREGNANCY AND POSTPARTUM}

Thromboembolism in pregnancy occurs in approximately 0.5 to 2.0 per 1,000 deliveries $[15,31,32]$. The risk for developing throm-

\author{
Hypercoagulation state \\ Factor VII, VIII, X, vWF $\uparrow$ \\ Increased venous stasis \\ Venous capacitance $\uparrow d /$ t hormonal influence \\ intravascular volume $\uparrow$ distends veins \\ Internal vena cava obstruction $d / t$ uterus
}

Anticoagulants decrease

Protein $S \downarrow$, acquired resistance to activated protein C

3rd trimester

Early puerperium

Vascular damage

Related to vaginal and cesarean section delivery (which create the greatest hypercoagulability during the early puerperium)

Fig. 1. Changes in the coagulation system during the third trimester of pregnancy and early puerperium. vWF, von Willebrand factor; $d / t$, due to. 
Table 1. Diagnostic criteria for preeclampsia [30]

\begin{tabular}{|c|c|}
\hline Blood pressure & $\begin{array}{l}\text { Systolic BP } \geq 140 \mathrm{~mm} \mathrm{Hg} \text { or diastolic } \mathrm{BP} \geq 90 \mathrm{~mm} \mathrm{Hg} \text { on two occasions at least } 4 \text { hours apart } \\
\text { after } 20 \text { weeks of gestation in a previously normotensive woman }\end{array}$ \\
\hline \multicolumn{2}{|c|}{ And the new onset of one or more of the following } \\
\hline \multirow[t]{3}{*}{ Proteinuria } & $300 \mathrm{mg} /$ day urine collection or \\
\hline & Protein/creatinine ratio $\geq 0.3$ or \\
\hline & Dipstick test $\geq 2+$ if other quantitative measurements are unavailable \\
\hline Thrombocytopenia & Platelet count $<100,000 / \mu \mathrm{L}$ \\
\hline \multirow[t]{2}{*}{ Renal insufficiency } & Serum creatinine $>1.1 \mathrm{mg} / \mathrm{dL}$ or \\
\hline & Doubling of the serum creatinine in the absence of other renal disease \\
\hline Hepatic dysfunction & Serum transaminase $>2$ times of upper limit of normal concentrations \\
\hline \multicolumn{2}{|l|}{ Pulmonary edema } \\
\hline Cerebral symptom & $\begin{array}{l}\text { New onset and persistent headache or visual symptoms (blurred vision, flashing lights, or } \\
\text { sparks) }\end{array}$ \\
\hline
\end{tabular}

Adapted from American College of Obstetricians and Gynecologists' Committee on Practice Bulletins-Obstetrics [30], with permission of Wolters Kluwer Health, Inc.

boembolism increases by a factor of 4 to 5 during pregnancy, and by up to 20 to 80 during the 3 months following delivery [33]. In particular, 2 weeks after delivery is the most critical period [34], accounting for approximately $10 \%$ of maternal mortality, resulting in 1.1 to 1.5 deaths per 10,000 deliveries [16].

Of pregnancy-related thromboembolisms, approximately $80 \%$ occur in the venous system, of which arterial thromboembolism accounts for 20\% [35]. There are various mechanisms of VTE. The most common complication of VTE is DVT, which occurs in $80 \%$ of patients with VTE. Pulmonary thromboembolism (PTE) is the second most common cause [35]. It is difficult to diagnose DVT or PTE in pregnant women because approximately $50 \%$ of patients exhibit no specific symptoms, and common lower extremity symptoms in DVT, or tachycardia, tachypnea or dyspnea in PTE can occur in women who are pregnant.

Cerebral venous thrombosis (CVT) accounts for $2 \%$ to $37 \%$ of pregnancy-associated strokes [36,37]. Clinical presentations of CVT are characterized by headache, papilledema, visual loss, motor deficits, seizures, focal neurological deficits, and altered mentality depending on the involved cerebral vein and sinus (Fig. 2) $[34,38]$. Compared with CVT unrelated to pregnancy and puerperium, pregnancy-related CVT has an acute onset with a progressive course and, more often, concomitant extraneurological thromboembolism. Nevertheless, CVT during pregnancy and puerperium can be diagnosed earlier and its symptoms tend to subside or become stable faster, thereby resulting in better outcomes with lower mortality [34].

\section{TREATMENT OF VTE DURING PREGNANCY AND POSTPARTUM}

Treatment of VTE during pregnancy is highly unique in many ways. Warfarin is a commonly used anticoagulant able to cross the placenta and may be teratogenic in the first trimester. In the third trimester, warfarin can increase the risk for bleeding in fetal intracranial bleeding $[39,40]$. Thus, its use during pregnancy should be avoided [41]. Direct oral anticoagulants are not recommended during pregnancy because their efficacy and safety have not been established, and should also not be used in women who are breastfeeding during puerperium [42]. The treatment of choice for VTE in pregnant women is subcutaneously administered low-molecular weight heparin (LMWH), which does not cross the placental barrier $[43,44]$. There is no fetal risk for bleeding or teratogenicity. Although intravenous (IV) unfractionated heparin can be considered as an alternative, subcutaneous LMWH is preferred over IV unfractionated heparin due to its higher bioavailability and a longer plasma half-life. Additionally, the use of LMWH is easier and appears to be more efficacious, with fewer bleeding complications $[16,41]$.

The proportion of patients who present with intracranial hemorrhages, such as venous hemorrhage, hemorrhagic infarction or, rarely, subarachnoid hemorrhage (SAH), represent approximately one-third of patients with CVT [45]. The presence of intracranial hemorrhage, however, is not a contraindication to anticoagulants in the management of CVT.

Reasonable initial dosing of subcutaneous LMWH is $1 \mathrm{mg} / \mathrm{kg}$ of enoxaparin every 12 hours, 100 units/ $\mathrm{kg}$ of dalteparin every 12 hours, or $200 \mathrm{units} / \mathrm{kg}$ of dalteparin once daily. LMWH should be 


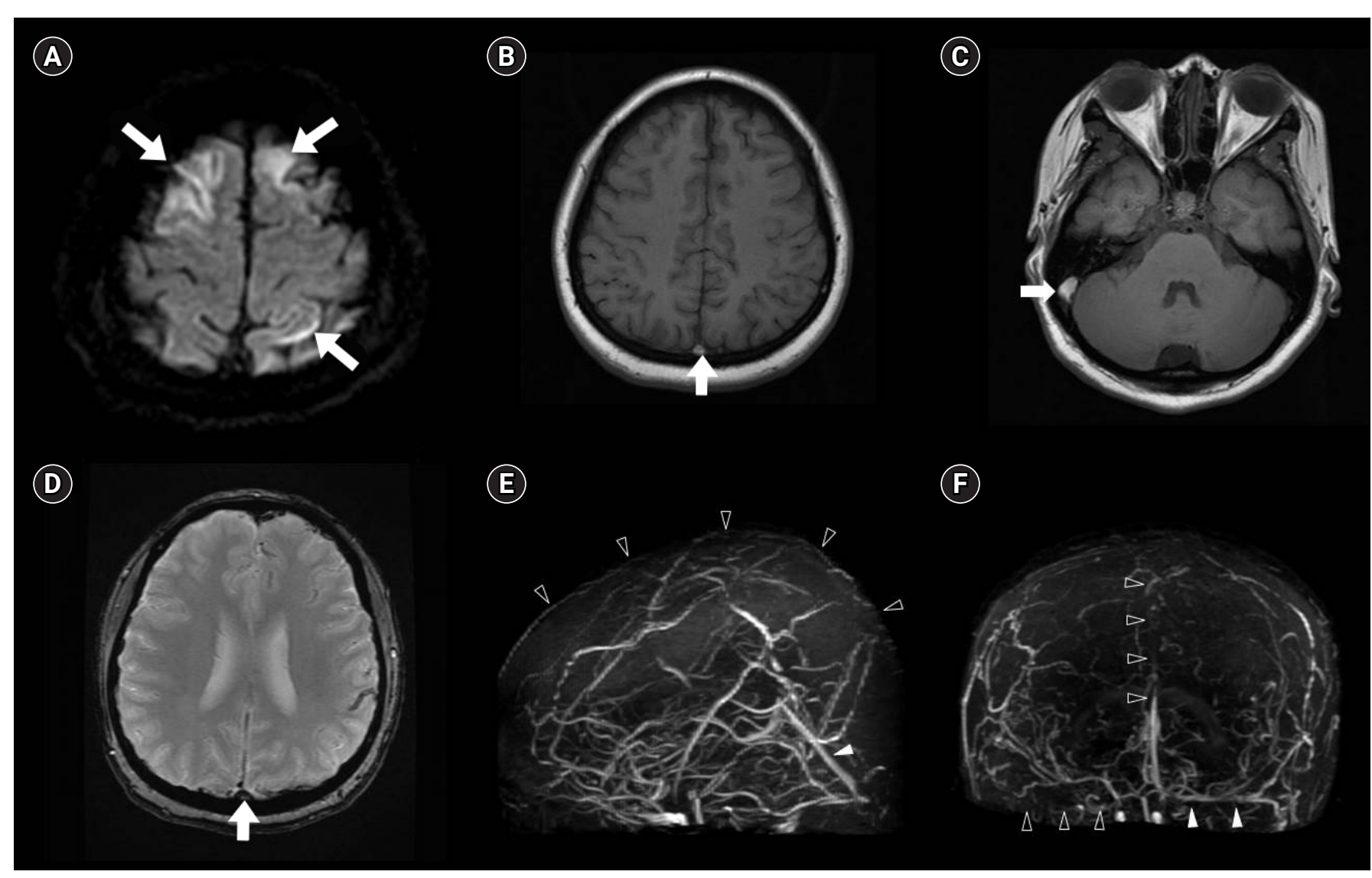

Fig. 2. Cerebral venous thrombosis. (A) Diffusion-weighted magnetic resonance (MR) imaging (MRI) revealing acute cerebral infarctions (arrows) at both frontal lobes. $(B, C) T 1$-weighted MRI revealing hyperintense signal of the thrombus at the superior sagittal sinus and right transverse sinus (filled arrows). (D) Gradient echo sequences demonstrating hypointense thrombus (filled arrow) in the superior sagittal sinus. (E) There is no superior sagittal sinus (arrowheads) detectable on coronal MR venography. (F) Sagittal MR venography demonstrates absent flow due to occlusion of the superior sagittal sinus and right transverse sinus (arrowheads). Filled arrowheads indicate straight sinus in (E) and left transverse sinus in (F).

discontinued 24 hours before induction of labor or cesarean section and resumed 4 to 6 hours after vaginal delivery, or 6 to 12 hours after cesarean delivery [46]. Treatment should be continued for at least 6 weeks after delivery. Although warfarin metabolites are detected in breast milk, their low activity makes it safe to use warfarin during lactation [47]. There are also no contraindications to breastfeeding while undergoing unfractionated heparin or LMWH therapy.

\section{ARTERIAL THROMBOEMBOLIC COMPLICATIONS DURING PREGNANCY AND POSTPARTUM}

Arterial thromboembolism is a less common complication but is, however, more critical and disabling. The incidence of pregnancy-associated stroke is 25 to 34 per 100,000 deliveries, a figure that has been rising steadily $[36,48]$. In comparison, the incidence of stroke unrelated to pregnancy in women 15 to 45 years of age is approximately 11 per 100,000 deliveries [49].

The risk for arterial ischemic stroke is higher during puerperium than during pregnancy. A previous study by Kittner et al. [50] reported that the risk for ischemic stroke increased in the puerperium period but not during pregnancy. Hemorrhagic stroke occurred more frequently during the second or early third trimesters, and in the early postpartum period. More specifically, the risk for aneurysmal SAH peaks at 30 to 34 weeks of pregnancy; however, intracerebral hemorrhage occurs more during puerperium than in pregnancy [50]. Approximately 50\% of all aneurysmal ruptures in women $<40$ years of age are pregnancy-related. Arteriovenous malformations (AVMs), however, are more controversial. One study reported that cerebral hemorrhage due to AVMs associated with pregnancy occurred evenly throughout the entire gestation and postpartum periods $[51,52]$.

Although there are many causes of stroke during pregnancy or 
puerperium, most are similar, with common etiologies such as ischemic or hemorrhagic stroke; however, pregnancy-specific causes include preeclampsia/eclampsia. Amniotic fluid embolism, AVMs, cerebral artery aneurysm, posterior reversible encephalopathy syndrome (PRES), and postpartum angiopathy (PPA) are also well-known causes [53-56].

\section{PRES AND PPA DURING PREGNANCY AND POSTPARTUM}

PRES is a clinical and radiographic syndrome and is classically characterized by vasogenic edema in the bilateral parietooccipital lobes (Fig. 3). Symmetrical hyperintense signals on T2 and fluid-attenuated inversion recovery magnetic resonance imaging, with increased value on the apparent diffusion coefficient map, can also be evident in atypical areas such as the basal ganglia, frontal lobes, cerebellum, and brainstem [57,58]. Approximately $20 \%$ of CVT can be accompanied by hemorrhagic stroke $[53,59]$. The mechanism is not completely understood; however, a breakdown of the blood-brain barrier and cerebral auto-regulation attributed to hyperperfusion results in extravasation of fluid containing blood by-products into the brain parenchyma, which in turn causes vasogenic edema. Endothelial dysfunction also plays a key role in the mechanism, and is especially associated with preeclampsia (Fig. 4). The levels of serological markers of endothelial dysfunction are increased during pregnancy with preeclampsia $[60,61]$. With regard to anatomical distribution, sympathetic innervation in the posterior circulation is relatively scant compared with the anterior circulation [62]. Sympathetic innervation of the intracranial arterioles has a protective role in rapid and dynamic fluctuations in blood flow. The posterior circulation, therefore, is vulnerable to breakthrough of the blood-brain barrier and failure of cerebral autoregulation.

PPA, one of the spectrums of reversible cerebral vasoconstriction syndrome, is a noninflammatory vasoconstrictive condition [63]. Two-thirds of PPA cases occur in the first week after delivery [64]. Patients with PPA exhibit reversible segmental constrictions and dilatations of large- or medium-size cerebral arteries (Fig. 5), and approximately $40 \%$ of PPA can be accompanied by intracranial hemorrhage [54]. PPA and PRES share many clinic-radiological features and pathophysiological mechanisms, and are considered to be overlapping conditions (Fig. 4) $[65,66]$. More than $85 \%$ of PRES exhibits multifocal vasoconstriction of the cerebral arteries and reversible cerebral edema occurs in approximately one-third of PPA cases. Both can present with thunderclap headache, seizure, and focal neurological deficits such as visual symptoms. Usually, however, they have a self-limited benign course, and radiological
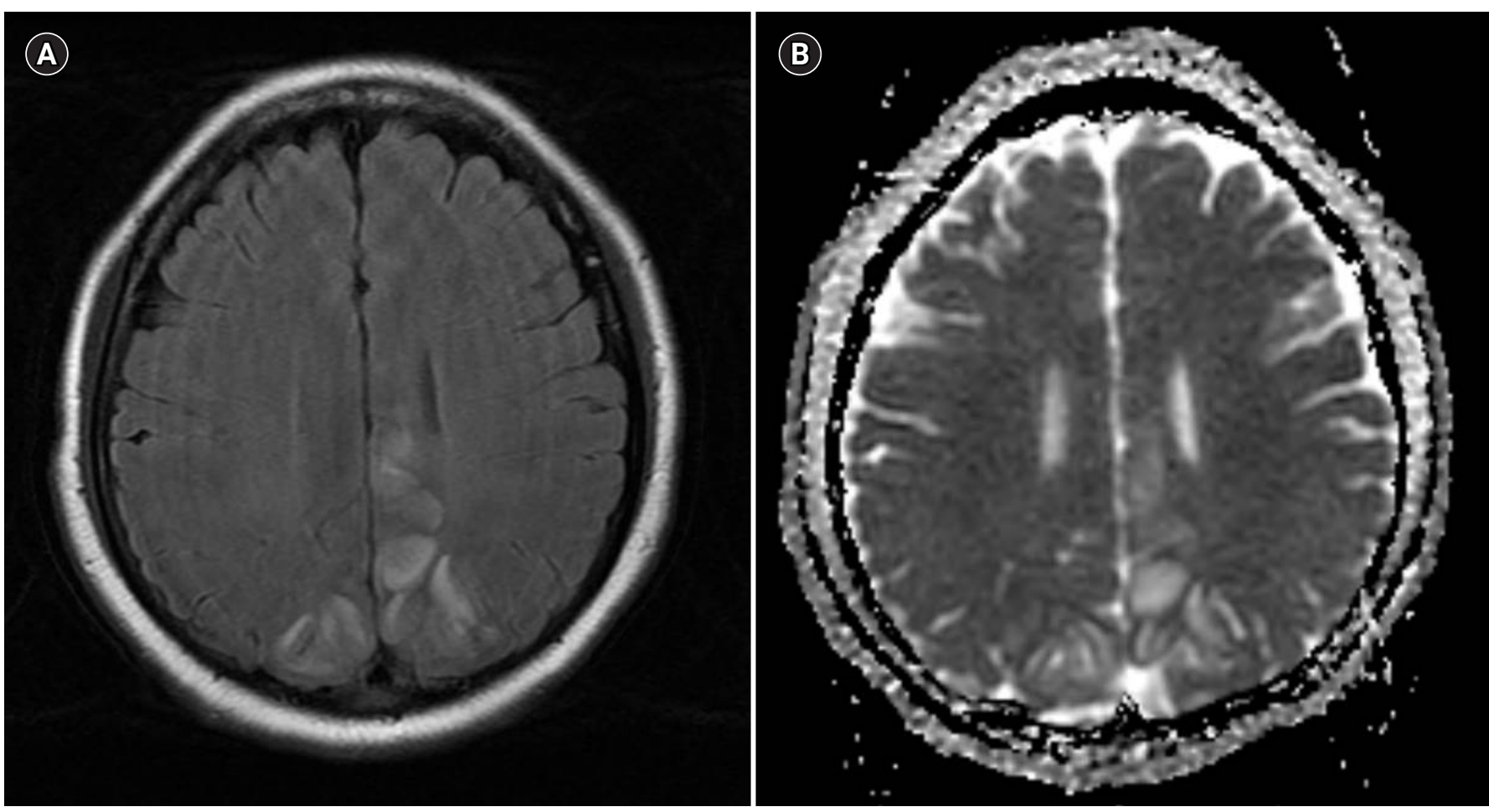

Fig. 3. Posterior reversible encephalopathy syndrome. (A) Axial fluid-attenuated inversion recovery magnetic resonance image revealing abnormal signal intensity in both parieto-occipital lobes. (B) Apparent diffusion coefficient map reveals increased values in the areas of fluid-attenuated inversion recovery abnormality, indicative of cortical vasogenic edema. 
abnormalities are resolved within several days to weeks [67]. Steroid is not a recommended therapy for pregnancy-associated PRES $[48,63]$. Although there is no supportive therapeutic evidence, short-term steroids, oral calcium channel blockers, and/or IV magnesium are administrated by some physicians for PPA [54]. As such, it remains controversial whether these treatments are effective in altering the natural disease course. However, $10 \%$ can be exacerbated by severe vasoconstriction and cerebral edema, leading to fulminant neurological deficits or death.

\section{TREATMENT OF STROKE DURING PREGNANCY AND POSTPARTUM}

The treatment of stroke during pregnancy and postpartum is guided by etiology and subtype. The safety of reperfusion strategies for pregnant women who experience acute ischemic stroke remains uncertain. IV alteplase does not cross the placenta because of its large molecular weight, but is listed as a pregnancy category $\mathrm{C}$ drug [68]. The major concern for administration of IV alteplase is the risk for maternal and fetal bleeding. Previous stroke guidelines have listed pregnancy as a relative exclusion criterion [69]. A recent study using the American Heart Association's Get With the Guidelines-Stroke Registry showed that 40 pregnant or postpartum

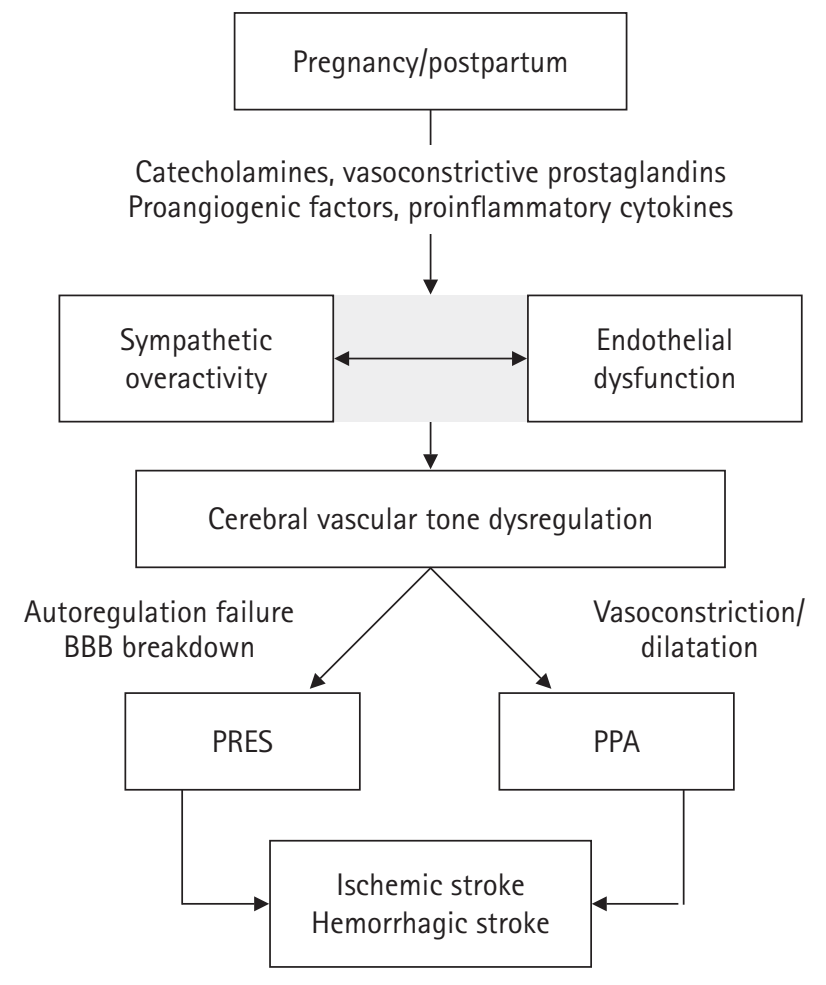

Fig. 4. The overlapping mechanism of postpartum angiopathy (PPA) and posterior reversible encephalopathy syndrome (PRES) during pregnancy and postpartum. BBB, blood-brain barrier.
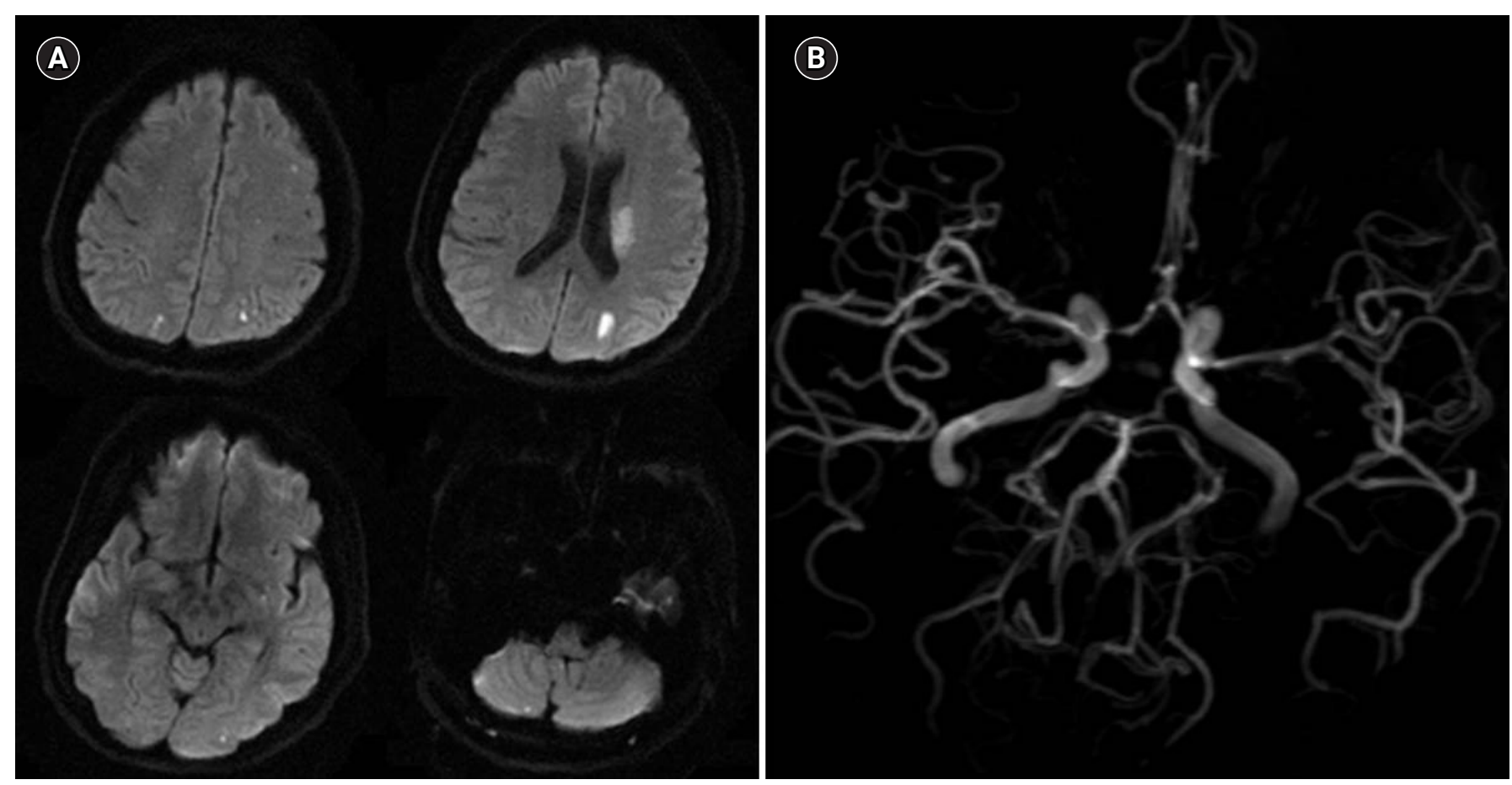

Fig. 5. Postpartum angiopathy. (A) Multiple acute cerebral infarctions in both cerebral hemispheres and right cerebellum. (B) Multifocal mild to moderate stenosis at both middle cerebral artery M2 segments, right anterior cerebral artery proximal A2 segment, right posterior cerebral artery (PCA) P1 segment, and left PCA P2 segment. 
women receiving emergent reperfusion therapy for acute ischemia exhibited a trend toward increased symptomatic intracranial hemorrhage compared with nonpregnant young women undergoing reperfusion therapy. However, they had more severe stroke severity, which is one of the major risk factors for symptomatic intracranial hemorrhage. Nevertheless, there were no significant differences in functional outcomes at discharge, life-threatening hemorrhage, and in-hospital mortality between pregnant or postpartum and nonpregnant women with ischemic stroke who received reperfusion therapy [70]. The updated 2018 American Heart Association/American Stroke Association guidelines reported that IV alteplase administration may be considered in the management of acute ischemic stroke for pregnant women when the anticipated benefit of IV alteplase outweighs the potential risk(s) for bleeding [71]. Recently, direct endovascular thrombectomy without IV alteplase has been attempted as an alternative treatment for pregnant women with a potentially high risk for bleeding on IV alteplase.

For antiplatelet therapy, the administration of aspirin can be considered in patients who experience acute ischemic stroke and have contraindications to anticoagulants [72]. Although ischemic stroke occurs less frequently during the first trimester of pregnancy, data regarding the safety of daily aspirin use during this period are limited. Aspirin can cross the placenta and increase the risk for birth defects. Therefore, daily use of aspirin is not recommended during the first trimester of pregnancy. In terms of the dose issue, highdose aspirin is not recommended due to the risk for congenital malformation and bleeding in the brains of premature infants [72]. Previous studies using low-dose aspirin in the second and third trimester; however, demonstrated no differences in congenital defects, developmental delay, or bleeding problems $[73,74]$. Based on this evidence, low-dose aspirin (60 to $150 \mathrm{mg}$ /day) can be used for ischemic stroke during the second and third trimesters of pregnancy [72]. There is a lack of evidence supporting the daily use of other antiplatelet medications, including clopidogrel (pregnancy category B) and dipyridamole (pregnancy category D) during pregnancy. Antithrombotic drugs should be discontinued before a planned delivery. Specific days depend on type: aspirin should be stopped 7 days before delivery, and LMWH should be discontinued 24 hours before delivery.

Early surgical clipping or endovascular coiling leads to better outcomes in pregnant women with $\mathrm{SAH}$ due to ruptured aneurysms $[7,75]$. Vaginal delivery can be safe after successful aneurysm obliteration. AVMs in pregnant women are also managed as they would in non-pregnant women. If an AVM bleeds during pregnancy, treatment depending on grade should be considered during the pregnancy [7]. Pregnant women should be always protected with shielding of the abdomen during radiological proce- dures and evaluations.

\section{BLOOD PRESSURE MANAGEMENT DURING PREGNANCY}

The National Institute for Health and Clinical Excellence recommends that management of hypertensive disorders during pregnancy should be initiated at blood pressures $\geq 150 / 100 \mathrm{~mm} \mathrm{Hg}$, and should be also used to maintain systolic blood pressure $<150$ $\mathrm{mm} \mathrm{Hg}$ and diastolic blood pressure of 80 to $100 \mathrm{~mm} \mathrm{Hg}$ [76]. However, all antihypertensive drugs can cross the placenta, and there are no comparative data regarding efficacy and fetal safety from large randomized trials. Labetalol, nifedipine, and methyldopa are recommended as primary options, and angiotensin-converting enzyme inhibitor, angiotensin receptor blocker, renin inhibitor, and mineralocorticoid receptor antagonist should be avoided due to increased risk for fetopathy [77]. If IV administration is required in the acute period of severe hypertension or pregnancy-related hemorrhagic stroke, hydralazine, labetalol, or nicardipine can be used primarily. Hydralazine ( $5 \mathrm{mg}$ IV administration for 1 to 2 minutes) is a drug widely used in the acute stage of severe preeclampsia and, if the reduction in blood pressure is insufficient, 5 to $10 \mathrm{mg} I V$ administration can be further injected further up to 30 $\mathrm{mg}$, with the drug effect lasting 2 to 4 hours. The initial dose of IV labetalol is $20 \mathrm{mg}$, and 20 to $80 \mathrm{mg}$ IV can be administrated repeatedly every 30 minutes up to $300 \mathrm{mg}$ in total. Blood pressure drops within 5 to 10 minutes and lasts 3 to 6 hours. Nicardipine can be administered intravenously in emergency cases. If the initial dose of $5 \mathrm{mg} / \mathrm{hr}$ is not effective, it can be increased to a maximum of 15 $\mathrm{mg} / \mathrm{hr}[78]$

\section{OTHER NEUROCRITICAL CARE DURING PREGNANCY}

In pregnant women with increased intracranial pressure due to various neurological complications, hypertonic saline is preferred over mannitol for osmotherapy. Mannitol can lead to fetal hypoxia and acid-base imbalances [17]. In terms of eclamptic seizure management, IV magnesium sulfate has been shown to be superior to commonly used anticonvulsants [79]. Typical dosing is 4 to $6 \mathrm{~g}$ over a period of 20 to 30 minutes, followed by continuous infusion of $2 \mathrm{~g} / \mathrm{hr}$. If seizures occur during treatment, additional $2 \mathrm{~g}$ boluses of IV magnesium sulfate may be administered.

\section{CONCLUSION}

Cerebrovascular complications during pregnancy and puerperium 
such as CVT, ischemic and hemorrhagic stroke, PRES and postpartum angiopathy present a challenge to neurointensivists because pregnancy is a very unique condition. Neurointensivists should understand the maternal changes in the hemodynamic, vascular structural, and coagulation systems that can occur during pregnancy and postpartum and also consider potential risk on the fetus. Knowledge of pregnancy-related cerebrovascular complications will provide optimal management for both fetus and mother.

\section{ARTICLE INFORMATION}

\section{Conflict of interest}

Dr. JH Hong is an editorial board member of the journal but was not involved in the peer reviewer selection, evaluation, or decision process of this article. There are no other potential conflicts of interest relevant to this article to declare.

\section{ORCID}

Jeong-Ho Hong, https://orcid.org/0000-0002-8235-9855

\section{Author contributions}

Conceptualization: JHH. Data curation \& Formal analysis: JHH. Visualization \& Writing-original draft: JHH. Writing-review editing: $\mathrm{JHH}$.

\section{REFERENCES}

1. Plauché WC. Myasthenia gravis in mothers and their newborns. Clin Obstet Gynecol 1991;34:82-99.

2. Confavreux C, Hutchinson M, Hours MM, Cortinovis-Tourniaire $\mathrm{P}$, Moreau T. Rate of pregnancy-related relapse in multiple sclerosis. Pregnancy in Multiple Sclerosis Group. N Engl J Med 1998;339:285-91.

3. Schmidt D, Canger R, Avanzini G, Battino D, Cusi C, Beck-Mannagetta $G$, et al. Change of seizure frequency in pregnant epileptic women.J Neurol Neurosurg Psychiatry 1983;46:751-5.

4. Otani K. Risk factors for the increased seizure frequency during pregnancy and puerperium. Folia Psychiatr Neurol Jpn 1985;39:33-41.

5. Reisinger TL, Newman M, Loring DW, Pennell PB, Meador KJ. Antiepileptic drug clearance and seizure frequency during pregnancy in women with epilepsy. Epilepsy Behav 2013;29:13-8.

6. Capeless EL, Clapp JF. Cardiovascular changes in early phase of pregnancy. Am J Obstet Gynecol 1989;161(6 Pt 1):1449-53.

7. Feske SK, Singhal AB. Cerebrovascular disorders complicating pregnancy. Continuum (Minneap Minn) 2014;20:80-99.

8. Gilson GJ, Samaan S, Crawford MH, Qualls CR, Curet LB.
Changes in hemodynamics, ventricular remodeling, and ventricular contractility during normal pregnancy: a longitudinal study. Obstet Gynecol 1997;89:957-62.

9. Silversides CK, Colman JM. Physiological changes in pregnancy. In: Oakley C, Warnes CA, editors. Heart disease in pregnancy. 2nd ed. Malden: Blackwell Publishing; 2007. p. 6-17.

10. Liu LX, Arany Z. Maternal cardiac metabolism in pregnancy. Cardiovasc Res 2014;101:545-53.

11. Anderson RJ, Berl T, McDonald KM, Schrier RW. Prostaglandins: effects on blood pressure, renal blood flow, sodium and water excretion. Kidney Int 1976;10:205-15.

12. Hull AD, Long DM, Longo LD, Pearce WJ. Pregnancy-induced changes in ovine cerebral arteries. Am J Physiol 1992;262(1 Pt 2):R137-43.

13. Marx GF. Aortocaval compression: incidence and prevention. Bull N Y Acad Med 1974;50:443-6.

14. Rabhi Y, Charras-Arthapignet C, Gris JC, Ayoub J, Brun JF, Lopez FM, et al. Lower limb vein enlargement and spontaneous blood flow echogenicity are normal sonographic findings during pregnancy. J Clin Ultrasound 2000;28:407-13.

15. Marik PE, Plante LA. Venous thromboembolic disease and pregnancy. N Engl J Med 2008;359:2025-33.

16. James AH. Thrombosis in pregnancy and maternal outcomes. Birth Defects Res C Embryo Today 2015;105:159-66.

17. Frontera JA, Ahmed W. Neurocritical care complications of pregnancy and puerperum. J Crit Care 2014;29:1069-81.

18. Abdul Sultan A, West J, Tata LJ, Fleming KM, Nelson-Piercy C, Grainge MJ. Risk of first venous thromboembolism in pregnant women in hospital: population based cohort study from England. BMJ 2013;347:f6099.

19. Tepper NK, Boulet SL, Whiteman MK, Monsour M, Marchbanks PA, Hooper WC, et al. Postpartum venous thromboembolism: incidence and risk factors. Obstet Gynecol 2014;123:98796.

20. Abdul Sultan A, Grainge MJ, West J, Fleming KM, Nelson-Piercy C, Tata LJ. Impact of risk factors on the timing of first postpartum venous thromboembolism: a population-based cohort study from England. Blood 2014;124:2872-80.

21. De Stefano V, Chiusolo P, Paciaroni K, Leone G. Epidemiology of factor V Leiden: clinical implications. Semin Thromb Hemost 1998;24:367-79.

22. Kim S, Song I, Kim HK, Huh S. Thrombophilia in Korean patients with arterial or venous thromboembolisms. Ann Surg Treat Res 2016;90:340-5.

23. Kim TW, Kim WK, Lee JH, Kim SB, Kim SW, Suh C, et al. Low prevalence of activated protein $C$ resistance and coagulation factor V Arg506 to Gln mutation among Korean patients 
with deep vein thrombosis. J Korean Med Sci 1998;13:587-90.

24. Grandone E, Margaglione M, Colaizzo D, D’Andrea G, Cappucci G, Brancaccio V, et al. Genetic susceptibility to pregnancy-related venous thromboembolism: roles of factor $\mathrm{V}$ Leiden, prothrombin G20210A, and methylenetetrahydrofolate reductase C677T mutations. Am J Obstet Gynecol 1998;179:1324-8.

25. Rosendaal FR, Reitsma PH. Genetics of venous thrombosis. J Thromb Haemost 2009; 7 Suppl 1:301-4.

26. Branch DW, Silver RM, Blackwell JL, Reading JC, Scott JR. Outcome of treated pregnancies in women with antiphospholipid syndrome: an update of the Utah experience. Obstet Gynecol 1992;80:614-20.

27. Bates SM, Greer IA, Middeldorp S, Veenstra DL, Prabulos AM, Vandvik PO. VTE, thrombophilia, antithrombotic therapy, and pregnancy: antithrombotic therapy and prevention of thrombosis, 9th ed: American College of Chest Physicians Evidence-Based Clinical Practice Guidelines. Chest 2012;141(2 Suppl):e691S-736S.

28. Bateman BT, Schumacher HC, Bushnell CD, Pile-Spellman J, Simpson LL, Sacco RL, et al. Intracerebral hemorrhage in pregnancy: frequency, risk factors, and outcome. Neurology 2006; 67:424-9.

29. Scott CA, Bewley S, Rudd A, Spark P, Kurinczuk JJ, Brocklehurst $\mathrm{P}$, et al. Incidence, risk factors, management, and outcomes of stroke in pregnancy. Obstet Gynecol 2012;120(2 Pt 1):318-24.

30. ACOG Practice Bulletin No. 202: Gestational hypertension and preeclampsia. Obstet Gynecol 2019;133:e1-25.

31. Heit JA, Kobbervig CE, James AH, Petterson TM, Bailey KR, Melton LJ 3rd. Trends in the incidence of venous thromboembolism during pregnancy or postpartum: a 30-year population-based study. Ann Intern Med 2005; 143:697-706.

32. James AH. Prevention and treatment of venous thromboembolism in pregnancy. Clin Obstet Gynecol 2012;55:774-87.

33. Konkle BA. Diagnosis and management of thrombosis in pregnancy. Birth Defects Res C Embryo Today 2015; 105:185-9.

34. Cantú C, Barinagarrementeria F. Cerebral venous thrombosis associated with pregnancy and puerperium. Review of 67 cases. Stroke 1993;24:1880-4.

35. James AH, Jamison MG, Brancazio LR, Myers ER. Venous thromboembolism during pregnancy and the postpartum period: incidence, risk factors, and mortality. Am J Obstet Gynecol 2006;194:1311-5.

36. James AH, Bushnell CD, Jamison MG, Myers ER. Incidence and risk factors for stroke in pregnancy and the puerperium. Obstet Gynecol 2005; 106:509-16.

37. Witlin AG, Friedman SA, Egerman RS, Frangieh AY, Sibai BM. Cerebrovascular disorders complicating pregnancy: beyond eclampsia. Am J Obstet Gynecol 1997;176:1139-45.

38. Bousser MG, Ferro JM. Cerebral venous thrombosis: an update. Lancet Neurol 2007;6:162-70.

39. Howie PW. Anticoagulants in pregnancy. Clin Obstet Gynaecol 1986;13:349-63.

40. Rutherford SE, Phelan JP. Thromboembolic disease in pregnancy. Clin Perinatol 1986;13:719-39.

41. Burgazlı KM, Bilgin M, Kavukçu E, Altay MM, Ozkan HT, Coşkun U, et al. Diagnosis and treatment of deep-vein thrombosis and approach to venous thromboembolism in obstetrics and gynecology.J Turk Ger Gynecol Assoc 2011;12:168-75.

42. Cohen H, Arachchillage DR, Middeldorp S, Beyer-Westendorf J, Abdul-Kadir R. Management of direct oral anticoagulants in women of childbearing potential: guidance from the SSC of the ISTH.J Thromb Haemost 2016; 14:1673-6.

43. Forestier F, Daffos F, Capella-Pavlovsky M. Low molecular weight heparin (PK 10169) does not cross the placenta during the second trimester of pregnancy study by direct fetal blood sampling under ultrasound. Thromb Res 1984;34:557-60.

44. Forestier F, Daffos F, Rainaut M, Toulemonde F. Low molecular weight heparin (CY 216) does not cross the placenta during the third trimester of pregnancy. Thromb Haemost 1987;57:234.

45. Wasay M, Bakshi R, Bobustuc G, Kojan S, Sheikh Z, Dai A, et al. Cerebral venous thrombosis: analysis of a multicenter cohort from the United States.J Stroke Cerebrovasc Dis 2008;17:49-54.

46. Arya R. How I manage venous thromboembolism in pregnancy. Br J Haematol 2011;153:698-708.

47. McKenna R, Cole ER, Vasan U. Is warfarin sodium contraindicated in the lactating mother? J Pediatr 1983;103:325-7.

48. Razmara A, Bakhadirov K, Batra A, Feske SK. Cerebrovascular complications of pregnancy and the postpartum period. Curr Cardiol Rep 2014;16:532.

49. Grear KE, Bushnell CD. Stroke and pregnancy: clinical presentation, evaluation, treatment, and epidemiology. Clin Obstet Gynecol 2013;56:350-9.

50. Kittner SJ, Stern BJ, Feeser BR, Hebel R, Nagey DA, Buchholz DW, et al. Pregnancy and the risk of stroke. N EnglJ Med 1996;335:76874.

51. Dias MS, Sekhar LN. Intracranial hemorrhage from aneurysms and arteriovenous malformations during pregnancy and the puerperium. Neurosurgery 1990;27:855-65.

52. Horton JC, Chambers WA, Lyons SL, Adams RD, Kjellberg $\mathrm{RN}$. Pregnancy and the risk of hemorrhage from cerebral arteriovenous malformations. Neurosurgery 1990;27:867-71.

53. Sharma A, Whitesell RT, Moran KJ. Imaging pattern of intracranial hemorrhage in the setting of posterior reversible encephalopathy syndrome. Neuroradiology 2010;52:855-63. 
54. Fugate JE, Ameriso SF, Ortiz G, Schottlaender LV, Wijdicks EF, Flemming KD, et al. Variable presentations of postpartum angiopathy. Stroke 2012;43:670-6.

55. Mas JL, Lamy C. Stroke in pregnancy and the puerperium. J Neurol 1998;245:305-13.

56. Feske SK. Stroke in pregnancy. Semin Neurol 2007;27:442-52. 57. Lamy C, Oppenheim C, Méder JF, Mas JL. Neuroimaging in posterior reversible encephalopathy syndrome. J Neuroimaging 2004; 14:89-96.

58. McKinney AM, Jagadeesan BD, Truwit CL. Central-variant posterior reversible encephalopathy syndrome: brainstem or basal ganglia involvement lacking cortical or subcortical cerebral edema. AJR Am J Roentgenol 2013;201:631-8.

59. Raman R, Devaramane R, Jagadish GM, Chowdaiah S. Various imaging manifestations of posterior reversible encephalopathy syndrome (PRES) on magnetic resonance imaging (MRI). Pol J Radiol 2017;82:64-70.

60. Savvidou MD, Hingorani AD, Tsikas D, Frölich JC, Vallance P, Nicolaides $\mathrm{KH}$. Endothelial dysfunction and raised plasma concentrations of asymmetric dimethylarginine in pregnant women who subsequently develop pre-eclampsia. Lancet 2003;361:1511-7.

61. Schwartz RB, Feske SK, Polak JF, DeGirolami U, Iaia A, Beckner KM, et al. Preeclampsia-eclampsia: clinical and neuroradiographic correlates and insights into the pathogenesis of hypertensive encephalopathy. Radiology 2000;217:371-6.

62. Edvinsson L, Owman C, Sjöberg NO. Autonomic nerves, mast cells, and amine receptors in human brain vessels. A histochemical and pharmacological study. Brain Res 1976;115:377-93.

63. Singhal AB, Hajj-Ali RA, Topcuoglu MA, Fok J, Bena J, Yang D, et al. Reversible cerebral vasoconstriction syndromes: analysis of 139 cases. Arch Neurol 2011;68:1005-12.

64. Ducros A, Bousser MG. Reversible cerebral vasoconstriction syndrome. Pract Neurol 2009;9:256-67.

65. Singhal AB. Postpartum angiopathy with reversible posterior leukoencephalopathy. Arch Neurol 2004;61:411-6.

66. Ducros A. Reversible cerebral vasoconstriction syndrome. Lancet Neurol 2012;11:906-17.

67. Singhal AB, Bernstein RA. Postpartum angiopathy and other cerebral vasoconstriction syndromes. Neurocrit Care 2005;3:91-7.

68. Leonhardt G, Gaul C, Nietsch HH, Buerke M, Schleussner E. Thrombolytic therapy in pregnancy. J Thromb Thrombolysis 2006;21:271-6.

69. Jauch EC, Saver JL, Adams HP Jr, Bruno A, Connors JJ, Demaerschalk BM, et al. Guidelines for the early management of patients with acute ischemic stroke: a guideline for healthcare professionals from the American Heart Association/American Stroke Association. Stroke 2013;44:870-947.

70. Leffert LR, Clancy CR, Bateman BT, Cox M, Schulte PJ, Smith EE, et al. Treatment patterns and short-term outcomes in ischemic stroke in pregnancy or postpartum period. Am J Obstet Gynecol 2016;214:723.

71. Powers WJ, Rabinstein AA, Ackerson T, Adeoye OM, Bambakidis NC, Becker K, et al. 2018 Guidelines for the early management of patients with acute ischemic stroke: a guideline for healthcare professionals from the American Heart Association/American Stroke Association. Stroke 2018;49:e46-110.

72. Kernan WN, Ovbiagele B, Black HR, Bravata DM, Chimowitz MI, Ezekowitz MD, et al. Guidelines for the prevention of stroke in patients with stroke and transient ischemic attack: a guideline for healthcare professionals from the American Heart Association/American Stroke Association. Stroke 2014;45:2160236.

73. CLASP collaborative group. Low dose aspirin in pregnancy and early childhood development: follow up of the collaborative low dose aspirin study in pregnancy. Br J Obstet Gynaecol 1995;102:861-8.

74. Roberge S, Bujold E, Nicolaides KH. Meta-analysis on the effect of aspirin use for prevention of preeclampsia on placental abruption and antepartum hemorrhage. Am J Obstet Gynecol 2018;218:483-9.

75. Meyers PM, Halbach VV, Malek AM, Phatouros CC, Dowd CF, Lawton MT, et al. Endovascular treatment of cerebral artery aneurysms during pregnancy: report of three cases. AJNR Am J Neuroradiol 2000;21:1306-11.

76. Visintin C, Mugglestone MA, Almerie MQ Nherera LM, James D, Walkinshaw S, et al. Management of hypertensive disorders during pregnancy: summary of NICE guidance. BMJ 2010;341:c2207.

77. American College of Obstetricians and Gynecologists; Task Force on Hypertension in Pregnancy. Hypertension in pregnancy. Report of the American College of Obstetricians and Gynecologists' task force on hypertension in pregnancy. Obstet Gynecol 2013;122:1122-31.

78. Kintiraki E, Papakatsika S, Kotronis G, Goulis DG, Kotsis V. Pregnancy-induced hypertension. Hormones (Athens) 2015;14:21123.

79. Which anticonvulsant for women with eclampsia? Evidence from the Collaborative Eclampsia Trial. Lancet 1995;345:145563. 